\title{
Constructions with Reflexive and Reciprocal Verbs in English and Armenian
}

\author{
Yelena Mkhitaryan, Mary Vardanyan \\ Yerevan State University
}

\begin{abstract}
Reflexive and reciprocal verbs constitute a special class both in the English and Armenian verbal system. As for their semantics, they manifest similarity, but morphologically and syntactically they show some differences. In English the meanings of reflexivity and reciprocity are expressed both by single verbs and their combination with the respective pronouns. In Armenian these categories are designated by means of the suffix l. The English reflexives may be used with the pronouns without apparent semantic change, whereas the Armenian counterparts normally do not take them. Used with other words than the respective pronouns these verbs lose the meanings of reflexivity and reciprocity and function as common transitive verbs.
\end{abstract}

Key words: reflexivity, reciprocity, self-pronoun, objectless transitive construction, symmetric action.

Reflexive and reciprocal verbs constitute a special class both in the English and Armenian verbal systems. Reflexive verbs show actions occurring within the same entity; reciprocal verbs indicate actions that are reciprocated by two or more entities (participants). In English the combinations of these verbs with the pronouns (self pronouns for reflexives and each other or one another for reciprocals) are often referred to as voice forms, since "the agent both acts and is acted upon" (Payne 2011:306). There have been various attempts to acknowledge two more voice forms in English: reflexive and reciprocal. Thus, B. Ilyish speaks of two approaches to the status of the pronoun in these constructions: 1) the pronoun is the auxiliary of the voice form, 2) the pronoun is a separate word functioning as a direct object (Ilyish 1971:116-119). M. Blokh claims that the reflexive and reciprocal pronouns within the framework of the hypothetical voice identification should be looked upon as the voice auxiliaries. The linguist concludes that this question is still open to consideration (Blokh 1983:181182). This problem becomes more complicated when the reflexive verbs dress, shave, wash, etc. and the reciprocal verbs part, divorce, kiss, etc. are used without the respective pronouns.

We think it rational to view these verbs in terms of structural dichotomy as it is suggested by some linguists. Thus, Th. Payne points out two types of reflexive and reciprocal verbs in English: lexical and analytic (Payne 2011:306-311). Lexical reflexives and reciprocals are represented by verbs only. Analytic verbs which are also referred to as syntactic reflexives and reciprocals are used with the respective pronouns.

Naturally, in the deep structure both the elements are present: the agent and the patient expressed by the verb and the reflexive or reciprocal pronoun, but in the surface 
structure the second element does not usually find explicit expression. So we can have equally: to wash oneself = to wash, to dress oneself = to dress, etc. or to divorce each other $=$ to divorce, to kiss each other $=$ to kiss. Semantically they preserve their reflexive and reciprocal meaning in both cases. Therefore almost all linguists agree that these verbs retain the category of reflexivity or reciprocity irrespective of the presence of the corresponding pronoun (Carter and McCarthy 2006:385-386). J. Lyons refers to these objectless verbs as implicit reflexives or reciprocals. The linguist argues that constructions with reflexive verbs preserve the meaning of reflexivity even when they occur without reflexive pronouns (Lyons 1978:383). The same can be said in regard to reciprocal verbs.

If a sentence contains more than one argument, there arises ambiguity as in the following sentences:

They want [John to help himself].

They want [John to help themselves].

A. Radford tries to interpret this phenomenon by introducing the concept of local antecedent. Accordingly, he claims that the first sentence is grammatically correct as the antecedent of the reflexive pronoun himself is the noun John contained within the same help-clause as himself. Conversely, the second sentence is ungrammatical because the reflexive pronoun themselves does not have an antecedent within the help-clause; its antecedent is contained in the want-clause, which is farther away (Radford 2006:92).

Now let us see what is the state of things with the reflexive and reciprocal verbs in Armenian. First of all it should be pointed out that both classes of verbs in English and Armenian show semantic similarity. As to their status in the Armenian verbal system, linguists display different approaches to this issue. We think the most rational definition is given by $\mathrm{H}$. Barseghyan, who claims that these verbs belong neither to active nor passive voice, since they cannot have an outer object; besides, and the agent is associated with the subject rather than the object (Barseghyan 1953:128-129). Another difference concerns the structure of the verb: in Armenian the categories of reflexivity and reciprocity

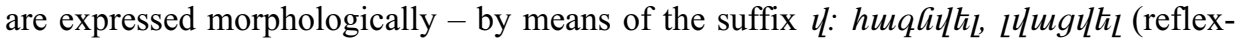

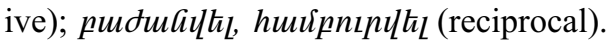

However, the Armenian reciprocals may occur in combination with the pronouns hnun, vhijuag. puдualligha hnunhg. But the presence of the reciprocal pronoun normally requires the verb in the active voice. Gnmap qnlumumnalkgha / Ginuap qnlkgha hnup, huifpnıplhgha/ hwifpnınhgha hnun (Asatryan 1970:190-191). As for the Armenian reflexives, they usually do not take the reflexive pronoun, though it is

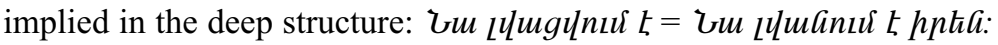

Below are examples to illustrate the morphological and structural differences between the uses of the English and Armenian reflexive and reciprocal verbs. ${ }^{1}$

a) He had just shaved for there was a white spot of lather on his cheekbone. 

цщшд:

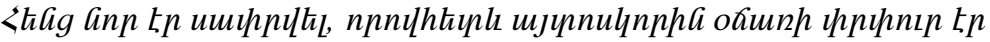

b) When Dick knocked, she had just dressed and been watching the rain..

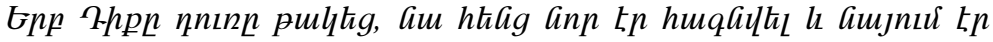
uąnliha...

c) In Sibyl's room they parted.

Uhph h ukajulnnu anwap puдuayhgha:

d) We kissed each other. I can't describe to you what I felt

at that moment.

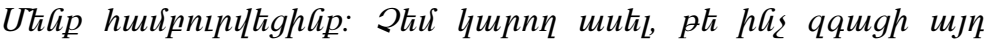
umhha:

English reflexive verbs are usually used without self- pronouns when they denote dailyroutine actions (I wash / dress / shave, etc.). However, used with reflexive pronouns they acquire new connotations. As R. Carter and M. McCarthy put it, used in this way these verbs would mean that a person is unable to do these things on his own or it may merely be an unexpected, surprising action (Carter and McCarthy 2006:385-386). In Armenian this meaning of the English reflexive is rendered by means of the adverb hapginınnıja.

e.g. a) She was no longer able to wash herself.

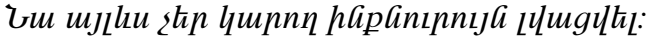

b) I was surprised to find out that she was able to wash herself that morning.

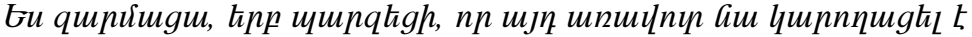
hapanınnıja hiqqaylit:

c) The child is old enough to wash herself.

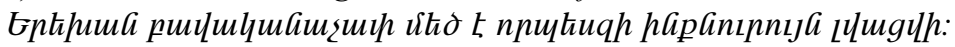

In other cases used with the reflexive pronoun the verb suggests that the action is done with deliberate care.

(Biber et al 2000:148)

e.g. a) There, since it would be in some sense an official visit, I dressed myself with care so as to make a proper impression on the captain.

b) So he had risen in the bitter cold of four-fifteen, washed himself in the prescribed fashion, dressed and put on his father's astrakhan cap.

Th. Payne also points to 'special situations' in which these verbs take reflexive pronouns.

e.g. a) The photographer had dressed himself in clothes that were less foppish than his usual attire.

b) Next, I bathed myself with a soapy cloth in the appropriate hygienic order. 
When reflexives are used without the pronoun, this may lead to ambiguity. Let us consider the following sentence:

e.g. He never shaves before lunch.

J. Lyons interprets this sentence in two ways: a) the man never shaves anybody before breakfast, b) he never shaves himself before breakfast. In the first case we deal with an objectless transitive verb, in the second case we have an implicit reflexive verb (Lyons 1978:383).

Below is another example adduced by $\mathrm{Ch}$. Kreidler.

1. Harvey drowned his mother-in-law.

2. Harvey drowned.

In the first example Harvey is the instigator of the action and his mother-in-law - a victim, i.e. the object. As to the second sentence, it is ambiguous. That would depend on whether Harvey committed suicide by drowning or he drowned accidentally. Whichever is the case, the information is not in the sentence (Kreidler 2002:79).

Verbs which are not characterized by reflexivity can take reflexive pronouns as direct objects, in which case they function as ordinary transitive verbs. This is observed in both English and Armenian.

a) He stooped and kissed her forehead.

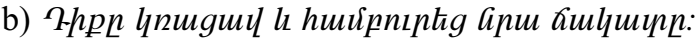

c) She washed the child in haste and put it in bed.

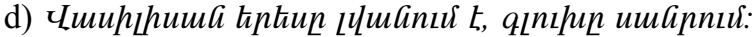

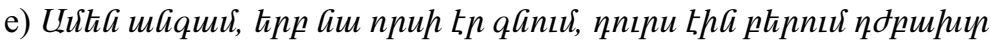

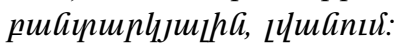

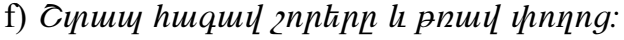

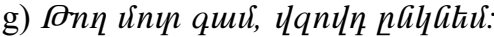

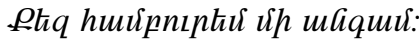

Reciprocal verbs basically function in the same way. As we have mentioned, English reflexives occur both with the reciprocal pronouns or without them. As for the choice of each other or one another, many linguists do not see any semantic difference between them. As M. Swan notes "if there is any difference, it seems to be that we prefer one another when we are making very general statements, and not talking about particular people." (Swan 1982:191-192). No difference is observed between the Armenian reciprocal pronouns hnun and vhijualig.

a) They adore one another.

b) Tuгinnui ka hnun:

c) But both of us loved each other all the time... 


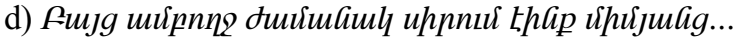

e) They are accusing one another vehemently.

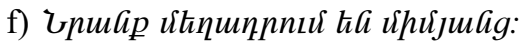

However, our factual material allows us to make the following observation: each other may show more intimacy, friendliness than one another. On the contrary, one another emphasizes distance, coldness in human relationship. Thus, when D. du Maurier describes the relations between the main characters Maxim and Caroline ("Rebecca") at different periods of their life, she uses one another to show a breach in their relationship, and each other when they regain their trust and love after a long period of bitter disappointment and distress.

e. g. a) He never spoke to me. He never touched me. We stood beside one another, the host and the hostess, and we were not together.

b) We can't lose each other now.

The English reciprocal verbs used without the pronouns denote:

1) emotional actions (embrace, kiss, hug)

a) When they kissed, he felt the same stirring.

b) They embraced and wept and promised to keep in touch.

c) They put their arms around each other and hugged.

2) communicative actions (talk, speak, interrupt, interrogate)

a) We talked on the phone for an hour.

b) Would you not mind interrupting all the time?

3) physical interaction (clash, collide, contact, fight)

a) They regularly collide over policy decisions.

b) Two men fighting over a parking space were arrested earlier today.

c) The two sets of supporters clashed outside the stadium.

4) mental interaction, cooperation (agree, argue, squabble, quarrel)

a) Ultimately the two sides could not agree, and negotiations were abandoned.

b) Jim and Beth seem to spend all their time arguing.

c) Whenever they meet they end up quarreling.

5) various forms of movement, joining, connection, disconnection (meet, divorce, join, link)

a) My parents divorced when I was seven years old.

b) How do these two pieces join?

c) We parted at the entrance. 
All these examples show that the actions of participants are symmetrical, therefore the omission of the object does not entail any semantic changes in the sentence. But as Ch. Kreidler claims it is not always the case. Let us consider the following two sentences:

1. The truck and the bus collided.

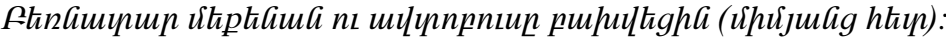

2. The truck collided with the bus.

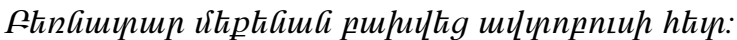

In the second case we cannot state that the actions of the participants are symmetrical: the truck collided with the bus, the same cannot be said about the bus.

As for the first example, it contains some kind of ambiguity. The truck and the bus collided may be assumed as the result of ellipsis. For example, we can assume that the truck and the bus collided with a taxi. Then we will have a) The truck collided with a taxi. b) The bus collided with a taxi (Kreidler 2002:107-109).

If the participants' actions are not symmetrical, the object is not deleted and the verb is not regarded as reciprocal. Consider the following sentences.

a) Landau embraced his protégé.

b) She kissed me swiftly, patting my shoulder at the same time...

c) She divorced her husband.

Here the verbs embrace, divorce and kiss function as ordinary transitive verbs taking a direct object. The same is observed in Armenian.

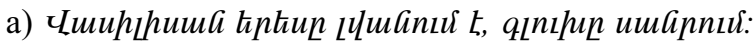

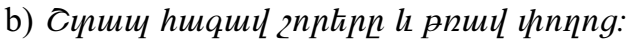

To conclude: English and Armenian reflexive and reciprocal verbs display similar semantic features but in other aspects they show some differences. Reflexives as well as reciprocals in Armenian are formed morphologically - by means of the suffix $\eta$. Reflexive verbs in Armenian do not usually combine with the respective pronouns, while reciprocal verbs may or may not take these pronouns. The analysis shows that objectless constructions with the lexical verbs under consideration are more common in use than those having the second element denoted by the reflexive or reciprocal pronoun. Reflexive and reciprocal verbs both in English and Armenian preserve the meanings of reflexivity and reciprocity irrespective of the presence or absence of the respective pronouns in the structure of the sentence. The presence of the self-pronoun in the construction may entail semantic changes in the meaning of the English reflexive construction. Objectless constructions with reflexive and reciprocal verbs in English may cause ambiguity, which can be removed by a wider context. Used with other words than the respective pronouns these verbs lose the categories of reflexivity and reciprocity and function as ordinary transitive verbs. 
Note:

1. The examples used in this paper are taken from various sources (dictionaries and fiction).

\section{References:}

1. Biber, D. et al (2000) Grammar of Spoken and Written English. London: Longman.

2. Blokh, M. (1980) A Course in Theoretical English Grammar. M.: Visshaya shkola.

3. Carter, R.; McCarthy, M. (2006) Cambridge Grammar of English. Cambridge: CUP.

4. Ilyish, B. (1971) The Structure of Modern English. Leningrad: Prosveshcheniye.

5. Kreidler, Ch.W. (2002) Introducing English Semantics. London and New York: Routledge.

6. Radford, A. (2004) English Syntax. An Introduction. Cambridge: CUP.

7. Payne, Th. (2011) Understanding English Grammar. Cambridge: CUP.

8. Swan, M. (1982) Practical English Usage. Oxford: OUP.

9. Lyons, J. (1978) Vvedeniye v teoreticheskuyu lingvistiku. M.: Progress.

10. Asatryan, M.E. (1970) Zhamanakakits hayots lezvi dzevabanutsyan hartser. Yerevan: Yerevani hamalsarani hratarakchutjun.

11. Barseghyan, H.Kh. (1953) Ardi hayereni bayi yev khonarhman tesutsyun. Yerevan: Yerevani hamalsarani hratarakchutyun.

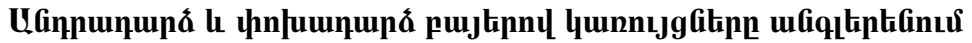 lu hujteptinuo}

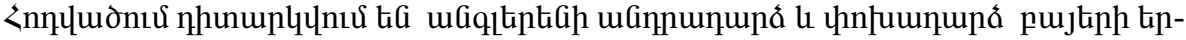

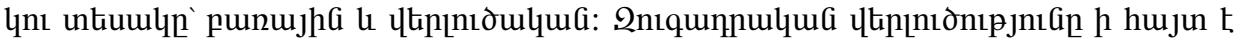

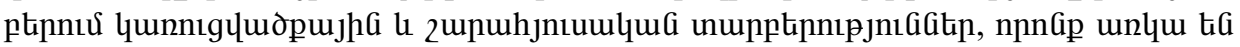

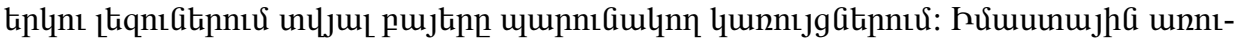

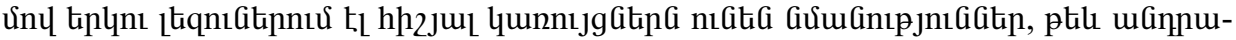

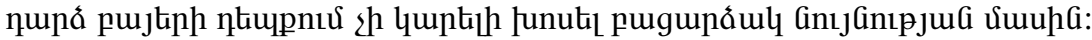

\section{Конструкщии с возвратными и взаимными глаголами в английском и армянском языках}

В статье рассматриваются два типа возвратных и взаимных глаголов в английском языке: лексические и взаимные. Сопоставительный анализ выявил те структурные и синтаксические различия, которые существуют между конструкциями с данными глаголами в обоих языках. В семантическом плане данные конструкции проявляют общие черты, за исключением конструкций с возвратными глаголами, где наблюдаются определенные различия. 